\title{
INFORME SEMINARIO DE REVISTAS BIOMEDICAS \\ 10o. CONGRESO COLOMBIANO DE MEDICINA INTERNA CARTAGENA - 6 DE AGOSTO DE 1988
}

Durante el Seminario de Revistas Biomédicas se presentaron dos panencias de los Directores del Acta Médica Colombiana de Bogotá y que a continuación transcribimos:

ESTRATEGIAS EN LA EDICION DE UNA REVISTA BIOMEDICA

Chelm F. Universidad Nacional de Colombia. Acta Médica Colombiana, Bogotá.

Esta comunicación se refiere a la estrategia seguida por el Comité Editorial de Acta Médica Colombiana que publica en forma ininterrumpida desde el año de 1976 y que se puede resumir en los siguientes puntos:

1. Ser el órgano de difusión de una institución científica importante, pero con autonomía para su manejo.

2. Desde el comienzo tener para la aceptación de los trabajos requisitos estrictos tanto por su originalidad, redacción, métudo científico y principios de ética.

3. Contar con un grupo de expertos para juzgar la calidad de los trabajos sometidos a publicación.

4. Desarrollo progresivo con cuatro números al año hasta llegar a seis suplementos. En un futuro próximo Acta Médica Colombiana podrá convertirse en una revista mensual.

5. En igual forma creación progresiva de secciones nuevas por iniciativa del Comité Editorial o por presión del material recibido.

6. Canjes y donaciones a facultades de medicina y hospitales del país y el extranjero.

7. Vinculación con los índices de la literatura médica nacional e internacional.

Se presentó también la ponencia del Dr. Roberto Esguerra del Acta Médica Colombiana así:

REQUISITOS UNIFICADOS PARA REVISTAS BIOMEDICAS

R. Esguerra. Fundación Santa Fe de Bogotá, Acta Médica Colombiana, Bogotá.

En 1978 un grupo de editores de Revistas Biomédicas se reunió con el fin de unificar los requisitos para el material enviado a sus revistas. Estos fueron publicados en un documento en 1979. Desde entonces se le han realizado dos revisiones (1982 y 1988), hasta llegar a la forma actual que será revisada periódicamente y ha sido aceptada por más de trescientas revistas de todo el mundo, entre las cuales se encuentra Acta Médica Colombiana.

Los requisitos son instrucciones a los autores sobre cómo preparar sus manuscritos para que puedan ser aceptados para publicaciones en una de las revistas participantes. Las instrucciones van desde la manera de preparar el manuscrito, incluyendo el tipo de papel que debe emplearse, su tamaño y las normas que deben observarse en la mecanografía y en la presentación del trabajo.

El trabajo debe contener en su orden: Página del título, resumen, texto, agradecimiento, referencias tablas y leyendas para las ilustraciones. El texto constituye el cuerpo de la publicación y debe contener: Introducción, métodos, resultados y discusión. En el caso de artículos extensos, las secciones de resultados y discusión pueden tener subdivisiones. Otros tipos de trabajos como los editoriales o la presentación de casos pueden requerir formatos especiales que cada revista especifica en las indicaciones a sus autores.

Las referencias deben seguir las indicaciones del Index medicus, y la abreviación del nombre de las revistas debe hacerse de acuerdo con su estilo. Las medidas de longitud, altura, peso y volumen deben informarse en unidades métricas. Todos los resultados de laboratorio deben estar en unidades del Sistema SI.

El documento también incluye guías para los informes estadísticos con el fin de ayudar a los autores a informar los aspectos estadísticos de su trabajo.

Fue muy importante para el Director de la Revista comprobar que la más antigua publicación Biomédica que durante 39 años se ha mantenido en forma ininterrumpida es la REVISTA COLOMBIANA DE OBSTETRICIA Y GINECOLOGIA, y que absolutamente todas las Revistas Colombianas que se editan hoy, tienen unificado el formato en tamaño carta, modificación que adoptamos a partir del Vol. XXXIX No.1 de 1988.

El Director de la Revista dejó una reseña histórica de nuestra publicación para los organizadores del Seminario de Revistas Biomédicas.

DR. GERMAN URIZA GUTIERREZ 